\title{
Watered-out Characteristic and Residual Hydrocarbon Potential Analysis of Central Distric of Xing6 in Daqing Oilfield, China
}

\author{
Weiqiang $\mathrm{Li}^{1 \mathrm{a}}$, Taiju $\mathrm{Yin}^{1 \mathrm{~b}}$, Aiwen $\mathrm{Zhao}^{1}, \mathrm{Lei}^{\mathrm{L}}{ }^{2}, \mathrm{Hai}_{\mathrm{Wu}}{ }^{3}$, Wen $\mathrm{Zhou}^{1}$ \\ ${ }^{1}$ College of Geoscience, Yangtze University, Wuhan, China \\ ${ }^{2}$ College of Geoscience, China University of petroleum, Beijing, China \\ ${ }^{3}$ Research Institute of Petroleum Exploration and Development, PetroChina, Beijing, China \\ aliweiq0608@163.com, b yintaij@yangzteu.edu.cn (Corresponding author)
}

Keywords: Watered-cut zone logging, Central distric of xing 6 in Daqing Oilfield, Channel sandbody, Interchannel sandbody, Untabulated reservoir, Degree of watered-out, Potential of residual hydrocarbon.

Abstract. Watered-cut zone logging technology is able to quantitatively obtain the remaining oil saturation and water cut of the underground reservoirs, to accurately judge the waterflooded grades of them, which is an important way and method to understand the distribution of residual hydrocarbon. The study shows that the overall watered out grades and ratio of the medium to high watered out are increasing year by year, whereas the low to non-watered out are decreasing year by year, which are all based on the statistics and analysis of watered cut zone logging of different well pattern periods in the central distric of xing6 in Daqing Oilfield. The statistics of the reservoirs of different sedimentary types has indicated that the waterflooded degree of channel sandbody is highest and the ratio of medium to high watered out is more than $96 \%$, and the percentage of interchannel sandbody is $69 \%$, however, these two kinds of reservoirs have not reach the stage of inefficient water injection which still have much potential of remaining oil. The untabulated reservoir is a special one in Daqing Oilfield and the producing degree of it is very low. The main reason why that case happened is that the scattered distribution in the plane makes the reservoir hard to be controlled by well pattern and the worse physical property puts it easier to be shielded by high-permeability layers when the reservoir adopts commingling production. Therefore, it is advisable to utilize the independent waterflooding development for the untabulated reservoir to improve the producing degree of it.

\section{Introduction}

Watered-cut zone logging is an important technology to study the distribution of remaining oil[1-5]. To quantitatively calculate the residual oil saturation and the water cut by the well logging curves provides a method to judge the watered out grades of underground reservoir and to better understand the watered out conditions[6-9]. Using the net-pay thickness interpreted by logging curves can divide the reservoirs of different sedimentary types into three types and the watered out conditions of them can be figured out through the statistics approach. Then the distribution location of residual hydrocarbon can be pointed out which can provide the basis and support for the further production adjustment.

The central distric of xing6 of Daqing Oilfield is located in a three-level structures in the central region of Daqing Changyuan of the Songliao Basin. The three-level structures lies in the north of Xingshugang structure, the central part of Xingshugang oilfield of which the area is $6.4 \mathrm{~km}^{2}$. Eight faults included in the research area in total are all normal fault with seal property and the fault strike is $\mathrm{NW}$ or NNW. The oil layers in the research area belonging to the large scale fluvial-deltaic depositional system have plenty of characteristics such as the long hydrocarbon bearing intervals, the numerous oil layers, the thin monolayer's thickness and so on. The study region develops three sets of oil layers from top to bottom which are Saertu, Putaohua and Gaotaizi oil layers.

The central distric of xing6 has been into production for 47 years since 1968 and designed four sets of well patterns with 678 development wells which respectively are 66 basic well pattern wells(put into production in 1968), 59 first-infill well pattern wells(put into production in 1986), 129 re-infill 
well pattern wells(put into production in 1996) and 417 third-infill well pattern wells(put into production in 2006). After many years of waterflooding development, the research area has been in high water cut stage with the highly scattered remaining oil and complex distribution conditions. Strengthening the understanding and tapping the production potential of the remaining hydrocarbon is the core work of development adjustment in oilfield at present.

This study is based on the results of watered out zone logging interpretation of four periods in the central distric of xing6 of Daqing Oilfield, the reservoirs divided into three types according to the net-pay thickness, and the waterflooded conditions of overall and three kinds of reservoirs at different well pattern stage are analyzed in a statistical approach, which indicates that the overall watered out degree is increasing year by year and channel sandbody and interchannel sandbody which remain the potential reservoirs of residual oil in the central distric of xing 6 are given priority to the medium and high watered out degree. Meanwhile, the untabulated reservoir is under low producing degree and the independent waterflooding development would be recommendable and efficient.

\section{Samples and Methods}

Adopting the statistical approach, based on the sub-layers data interpreted by watered out zone logging curve of 678 development wells in the central distric of Xing6 of Daqing Oilfield, classifying the well data of different well pattern periods into four stages, this study conducts statistics for the overall waterflooded conditions of the four well pattern periods in research area. Then the reservoirs of different sedimentary types are divided into three patterns which are the channel sandbody(its net-pay thickness is greater than $1 \mathrm{~m}$ ), interchannel sandbody(its net-pay thickness is between $0 \mathrm{~m}$ and $1 \mathrm{~m}$ ) and untabulated reservoir(its net-pay thickness is $0 \mathrm{~m}$ but sandstone thickness is greater than $0 \mathrm{~m}$ ) according to logging interpretation results of the sub-layers data. Following the previous step, the waterflooded conditions of different sorts of reservoirs in four well pattern stages are analyzed with statistical method and so does the potential of residual hydrocarbon of them.

\section{Results and Discussion}

The overall watered out conditions. From the basic well pattern period to the third-infill well pattern period, the water cut degree strengthens with years and the percentage of non-watered out decreases quickly, meanwhile, the percentage of medium to high watered out increases rapidly. The reservoir of basic well pattern period is the original reservoir which remains undeveloped. Therefore, the watered out degree of this period is lowest with 90\% non-watered out and the degree of reserve recovery and the composite water cut are all quite low. With the waterflooding development going on, the producing condition, the degree of reserve recovery, the proportion of medium to high watered out thickness and the composite water cut of the underground reservoir all increase from the basic well pattern period to the third-infill well pattern period, however, the percentage of high waterflooded decreases to some extent because the waterflooded zone interpretation of the second-infill well pattern(re-infill well pattern) is aimed at thin oil layers whose net-pay thickness is less than $0.5 \mathrm{~m}$ and the untabulated reservoir and the overall watered out degree of them is very low which makes the part of high waterflooded decreasing and low waterflooded increasing at the re-infill well pattern period. When the third-infill well pattern comes, the percentage of medium to high watered out thickness is more than $74 \%$ which indicates the research area is mainly in medium to high waterflooded condition but there is still nearly $26 \%$ of the low to non-watered out parts(Fig.1a).

The channel sandbody watered out conditions. It is observed that the percentage of medium to high watered out increases sharply from the basic well pattern period to the first-infill well pattern period, especially the high watered out proportion enlarged 7 times than it of the basic well pattern period and the non-watered out decreased to one fifth of the former period, according to the waterflooded condition statistics of channel sandbody at the four well pattern stages(Fig.1b). The high and non-watered out proportion rises and falls respectively from the first-infill well pattern stage to the third-infill well pattern period, except that the percentage of high watered out reduced because 
the re-infill well pattern is aimed at thin oil layers whose net-pay thickness is less than $0.5 \mathrm{~m}$ and the untabulated reservoir. Therefore, the waterflooded degree of channel sandbody in the study area to date is mainly the medium to the high whose proportion of waterflooded net-pay thickness is more than $96 \%$ and is overwhelmingly dominated than the low to non-watered out. Even though the medium to high parts are so huge, the oil displacement efficiency of these reservoirs has not reach the upper limit value of $69 \%$ of the inefficient water injection period yet, most encouragingly, which demonstrates that the residual oil potential is still existing in the medium to high waterflooded reservoirs.

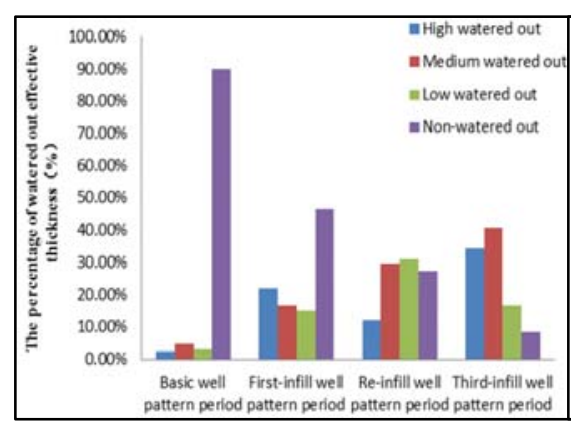

(a)

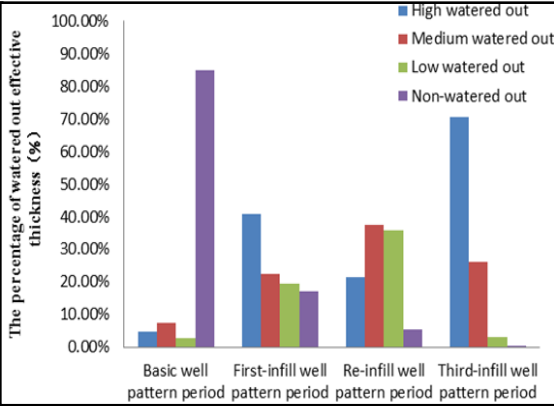

(b)

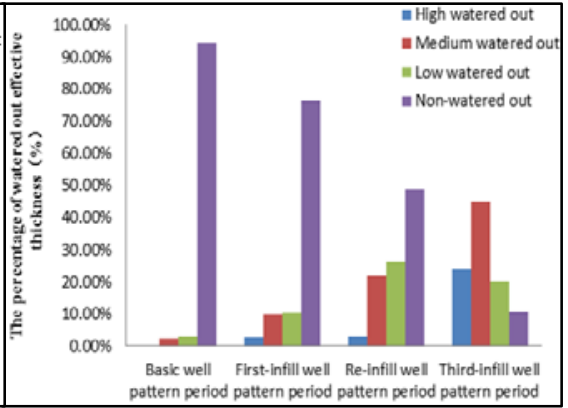

(c)

Fig. 1 The statistical results of watered out conditions of different well pattern periods in the study area: (a) The overall watered out conditions;(b) The channel sandbody watered out conditions;(c) The interchannel sandbody watered out conditions

The interchannel sandbody watered out conditions. The statistics results of the interchannel sandbody at different well pattern suggests that the watered out degree of the reservoir is weaker than the channel sandbody. As illustrated in Fig.1c, there is not high waterflooding area at the basic well pattern period until the first-infill well pattern period with the percentage of $2.85 \%$. The proportion of high watered out at the re-infill well pattern period slightly rises to 3\% compared with the first-infill well pattern period but the medium to the low waterflooded increases significantly. From the re-infill well pattern period to the third-infill well pattern period, on the one hand, the proportion of the latter increases up to eightfold of the former and the medium waterflooded is up to one time higher than that of the former period, on the other hand, the proportion of non-watered out thickness decreases approximately to the one fifth of the re-infill well pattern period which represents the prominent producing condition of that. As a consequence, the potential of the remaining hydrocarbon primarily distributes in the reservoir of the medium to the high waterflooded but the low to non-watered out reservoir still owns considerable residual oil potential, with the proportion of $69 \%$ and $31 \%$ respectively.

The untabulated sandbody watered out conditions. The untabulated reservoir of Daqing Oilfield consists of the sediments of low-energy environment in the fluvial-deltaic system which are mainly argillaceous siltstone characterized by oil soaking and oil stain of the oil-bearing occurrence[10]. This sort of reservoir distributes on the top, bottom and periphery of channel sandbody and other high-energy environment reservoir. Generally, the untabulated reservoir cannot be classified as net-pay thickness within the lower limits so that it is not included in the reserve table, therefore, this kind of reservoir is called the untabulated reservoir.

It is concluded that the producing degree of the untabulated reservoir is basically under unproduced and the overall watered out degree of it is quite low which is primarily non-watered out degree. The main reason is that the scattered distribution in the plane makes the reservoir hard to be controlled by well pattern and the worse physical property puts it easier to be shielded by high-permeability layers when the reservoir adopts commingling production. In the production adjustment of the future, it is considerable to employ the independent waterflooding development for the untabulated reservoir to improve the producing degree of it. 


\section{Conclusions}

From the basic well pattern period to the third-infill well pattern period, the medium to high watered out degree increases and the low to non-watered out degree decreases year by year in the central distric of Xing6 of Daqing Oilfield. The overall waterflooded condition of the research area is mainly the medium to the high watered out and the proportion of its thickness has been greater than $74 \%$ by now. According to the statistics results of the waterflooded condition of different reservoirs, it is clear to observe that the watered out degree of channel sandbody is the highest and the percentage of the medium to the high waterflooded of that exceed $96 \%$, meanwhile, the ratio of the interchannel sandbody is more than $69 \%$ as well. Whether the channel sandbody or the interchannel sandbody, the oil displacement efficiency of them is under the upper limit of $69 \%$ of the inefficient water injection period which are still the important potential reserves of remaining oil in the central distric of Xing6. The potential of the low to non-watered out primarily distributes in the interchannel sandbody and the untabulated reservoir.

\section{Acknowledgment}

This paper was supported by the National Natural Science Foundation of China(No. 41072087) and the key state science and technology project(No. 2011ZX05010-002-005). The authors wish to thank CNPC Daqing Oilfield Research Institute of Petroleum Exploration and Development for supplying research data.

\section{References}

[1] S. Wang, Y. Yang and W. Jiang. Reservoir evaluation logging for waterflooding oilfields. Beijing, China: SPE,1998, pp21-29.

[2] P. L. Hedges and S. Moothart. Infill well water-cut estimates based on open hole log data in a mineralogically complex reservoir: Kuparuk River Field Alaska. Anchorage, AK, USA: SPE,1996, pp343-350.

[3] J. Ci, S. He, Z. Li, M. Wang, J. Cui, and Y. Jiang "Present situation of waterflooded zone logging and its developing trend". Natural Gas Industry,2005, vol25,pp 44-46+7.(in chinese)

[4] S. Song, G. He and C. Tan. Research on the log interpretation method of the waterflooded formation in Hanan Oil Field. Journal of Xi'an Petroleum Institute (Natural Science Edition), 1999, vol14, pp33-35, 57. (in chinese)

[5] M. K. Lerma. Analytical Method to Predict Waterflood Performance. Long Beach, CA, United states : SPE, 2003,pp285-296.

[6] C. Liu, W. Yan, Q. Yang, and H. Ma. Logging response characteristic analyses and saturation calculation method for polymer flooded reservoir. Beijing, China: SPE, 2010,pp1964-1971.

[7] P. Pathak, D. E. Fitz and K. P. Babcock. Residual oil saturation determination for EOR projects in a mature west texas carbonate field. Kuala Lumpur, Malaysia: SPE,2011, pp1616-1634.

[8] L. F. Elkins and R. E. Poppe. Determining residual oil saturation behind a waterflood - a case history. Journal of Petroleum Technology, 1973,vol25, pp1237-1243.

[9] R. P. Murphy, G. T. Foster and W. W. Owens. Evaluation of waterflood residual oil saturations using log-inject-log procedures. SPE, 1976,pp87-103.

[10]Q. Wang. The study and development of the untabulated reservoir in Daqing Oilfield. Foreign Oilfield Engineering, 1998,vol1, pp5-8. (in chinese) 